\title{
Antileishmanial Steroidal Alkaloids from the Plant Sarcococca wallichii Stapf
}

\author{
Achyut Adhikari, ${ }^{*}$ and M. Ismail Vohra ${ }^{2}$ \\ ${ }^{I}$ Central Department of Chemistry, Tribhuvan University, Kirtipur, Kathmandu, Nepal. \\ ${ }^{2}$ HEJ Research Institute of Chemistry, ICCBS, University of Karachi, Karachi, Pakistan. \\ E-mail: adhikarimine@yahoo.com
}

\begin{abstract}
Bioassay guided isolation of compounds from the plant Sarcococca wallichii has yieldes four antileishmanial compounds: dictyophlebine (1) N-methylpachysamine $A$ (2), sarcodinine (3), and sarcorine (4) from the dichloromethane fraction at $\mathrm{pH} 9$, which was significantly active against Leishmanial tropica. Structures of the compounds were deduced using mass spectrometry and 1D-and 2D-NMR spectroscopy. Compounds 1-4 were tested against L. tropica and found to be moderate to significant active with IC 50 values: $18.9 \pm 0.7,37.1 \pm 0.8,29.9 \pm 0.1,30.1 \pm 0.1 \mu \mathrm{g} / \mathrm{mL}$, with compared to standard drug pentamidine $I C_{50}=5.09 \pm 0.09 \mu \mathrm{g} / \mathrm{mL}$.
\end{abstract}

Keywords: Sarcococca wallichii, antileishmanial, Leishmanial tropica, steroidal alkaloids

\section{Introduction}

S. wallichii is a one of the species from numerous species of the genus Sarcococca, is also known as Sweet Box Wallichii. ${ }^{1}$ Four species namely S. coriacea, S. saligna, S. hookerina, and S. wallichii are found in Nepal. ${ }^{2} S$. wallichii stapf. is a shrub, 0.6-3 m tall, branchless, erect or curved toward left or right, sometimes longer and slender, trailing, longitudinally ribbed, glabrous, with long sharp shiny evergreen leaves which grow up to $2 \mathrm{~m}^{2}$ It is widely distributed in central Nepal at altitudes of above $2300 \mathrm{~m}^{2}$

Leishmaniasis is a disease caused by the protozoan parasite, such as Leishmania infantum, L. donovani, L. major, L. aethiopica, L. brasiliensis, L. tropica, etc. Leishmaniasis is wide spread all over the tropical and sub-tropical regions of Africa, Southern Europe, South and Central America, Asian and Mediterranean regions. ${ }^{3}$ L. tropica is a is a species of flagellate parasites that nfects humans and hyraxes, and the cause of the disease Leishmaniasis Recidivans, a form of cutaneous leishmaniasis. ${ }^{3}$ According to earlier literature, almost 12 million population found to be infected due to the disease and 340 million citizens of the continents Asia, Africa, Europe, and America has been suffering from this threat. ${ }^{4}$ Some synthetic drugs are used in the chemotherapy of leishmaniasis, many of which are not so effective or toxic to the host. Some drugs such as stibamine, megulamine antimoniate, sodium stibogluconate etc., cause harsh undesirable effects. Some of the drugs such as amphotericin B and pantamidine, which are in current use, are toxic and nonresponsive and failure of treatment is also common. ${ }^{5,6}$ Leishmaniasis is a neglected tropical disease, and has been neglected by big companies for drug development due to its low

${ }^{*}$ Corresponding author 
economic feasibility for pharmaceutical companies. So there is an urgent need to exploration for the development of efficient, potent and nontoxic medicines to fight with the painful disease.

Steroidal alkaloids have been reported as antileishmanial against L. major. ${ }^{7,8}$ In our previous work we have reported anti-inflammatory activity of compounds from this plant. ${ }^{9}$ In this report, antileishmanial activitity of compounds from $S$. wallichii against parasite L. tropica is presented.

\section{Experimental Methods}

\section{General experimental}

Optical rotations were recorded on a JASCO digital polarimeter (model DIP-3600) in chloroform and methanol. Purity of compound was confirmed using pre-coated silica gel TLC $(20 \times 20,0.5 \mathrm{~mm}$ thick, E. Merck, type 70-230 Mesh), were examined under UV light at 254 and $366 \mathrm{~nm}$. Spots on TLC plates were further confirmed by spraying with Dragendorff's solution.

Jeol MS route JMS $600 \mathrm{H}$ attached with TSS 2000 was used to record EI-MS. The HREI-MS measured on Thermo Finnigan MAT 95XP attached with X-calibur. Jeol JMS-HX 110 attached with TGRAF-4200 mass spectrometer was used for the FAB-MS (Fast Atom Bombardment Mass Spectrum) and HRFAB-MS (High Resolution Fast Atom Bombardment). The IR spectra were acquired from FTIR8900 (Fourier Transform Infrared Spectrophotometer, Shimadzu, Japan) using KBr disc. UV/Visible spectra were acquired from Evolution UV-Visible spectrophotometer (Thermoscientific, United State) in $\lambda_{\max }(\varepsilon)$. Polarimeter P-2000 (JASCO, Japan) was used to measure optical rotations. All 1D- and 2DNMR spectra were recorded on Avance 300, 400 and $500 \mathrm{MHz}$ instruments.

\section{Plant material}

Aerial component of Sarcococca wallichii was gathered from Dhampus, Kaski, Nepal, and recognized by Prof. Krishna Kumar Shrestha, Central Department of Botany, Tribhuvan University, Kritipur, Kathmandu, Nepal. Plant herbarium (Voucher specimen No: SW-06) has been deposited in the same section.

\section{Extraction and isolation of compounds 1-4}

Air- dried plant material $(10.0 \mathrm{~kg})$ of $S$. wallichii was dipped in $80 \%$ methanol/water $(60 \mathrm{~L})$ and filtered after one week. The extract $(1.0 \mathrm{~kg})$ was obtained after evaporation of filtrate in vacuum, after that extract was dissolved in distilled water and defatted with Hexane $(20 \mathrm{~L}),(50.0 \mathrm{~g}, \mathbf{S W}-\mathbf{A})$. The aqueous layer was then fractionated with DCM $(20 \mathrm{~L})$ to obtain "neutral fraction" $(40.0 \mathrm{~g}, \mathbf{S W}-\mathbf{B})$. Ammonia solution was added to aqueous layer to make it alkaline ( $\mathrm{pH} 9-10)$ and again fractionated with DCM $(20 \mathrm{~L})$ to obtain "alkaline fraction" $(22.0 \mathrm{~g}, \mathbf{S W}-\mathrm{C})$.

On the basis of the bioassay results, the "alkaline" fraction SW-C was chromatographed over silica gel, using hexanes and acetone as an eluting agent, which afforded a number of fractions SW-C1 -SWC6. Fraction SW-C1 (2.0 g) was subjected over alumina column chromatography, which yielded three major sub-fractions 2A, 2B, 2C, and 2D. Compounds 1, 2, 3, and 4 were obtained after repeated chromatography of sub-fractions $\mathbf{2 A}, \mathbf{2 B}, \mathbf{2 C}, \mathbf{2 D}$ over alumina using hexanes and diethyl amine as eluting agent. 


\section{Antileishmanial assay}

Modified NNN biphasic medium on normal physiological saline was used to grow Leishmania promastigotes in bulk. RPMI 1640 medium, supplemented with 10\% heat inactivated fetal bovine serum (FBS) was used to culture Leshmania parasite promastigotes. Parasites were centrifuged for 10 minutes at $2000 \mathrm{rpm}$ and washed three times with saline and diluted to a final density of $1 \times 10^{6}$ cells $/ \mathrm{ml}$ using fresh culture medium. Solution of compounds to be checked were prepared by dissolving $1.0 \mathrm{mg}$ in $0.1 \mathrm{~mL}$ of PBS (Phosphate Buffered Saline, pH 7.4 containing 0.5\% MeOH, 0.5\% DMSO). $180 \mu L$ of medium was poured in first row of 96-well micro titer plate and $100 \mu L$ to other wells. $20 \mu L$ of the solution of tested compound was added in medium followed by serial dilution. Parasite culture $(100 \mu L)$ was poured in all wells. Two rows were considered for negative and positive controls. In negative control only medium was added, while the positive control possesses standard antileishmanial compound e.g. amphotericin $\mathrm{B}$ and pentamidine in different concentrations. The plate was put in incubator at temp between $22-25^{\circ} \mathrm{C}$ for 72 hours. Microscope was used to examine the culture and cells were counted using improved neubauer counting chamber. Software Ezfit 5.03, Perella Scientific was used to calculate the $\mathrm{IC}_{50}$ values. All assays were performed twicely. ${ }^{10,11}$

\section{Results and Discussion}

Compound 1 (Fig-1), $[\alpha]_{\mathrm{D}}{ }^{25}=+24(c=0.04, \mathrm{MeOH})$ was obtained from the $\mathrm{pH} 9$ dichloromethane extract of S. wallichii . Only terminal absorptions appeared on UV spectrum. Absorptions at $3350(\mathrm{NH})$ and $2927(\mathrm{CH}) \mathrm{cm}^{-1}$ were appeared on IR spectrum. The EI-MS spectrum displayed molecular ion peak at $m / z 360$, which was more supported by the $\mathrm{FAB}^{+\mathrm{ve}} \mathrm{MS}$ which showed $\mathrm{M}^{+}+\mathrm{H}$ peak at $m / z$ 361. Its molecular formula $\mathrm{C}_{24} \mathrm{H}_{44} \mathrm{~N}_{2}$, was deduced from HREI-MS, which showed molecular ion peak at at $\mathrm{m} / \mathrm{z}$ $360.3161\left(\mathrm{C}_{24} \mathrm{H}_{44} \mathrm{~N}_{2}\right.$, Calcd 360.3188). The EI MS displayed the three fragments at $\mathrm{m} / z 345(4.7 \%)$ and 72 (100\%). The ${ }^{1} \mathrm{H}$ - and ${ }^{13} \mathrm{C}$-NMR spectral data of compound 1 was unambiguously matched with compound dictyophlebine. ${ }^{12}$

Compound 2, $[\alpha]_{\mathrm{D}}{ }^{28}=+18(c=0.03, \mathrm{MeOH})$, was acquired as a white amorphous solid from the $\mathrm{pH} 9$ DCM extract of $S$. wallichii. The UV spectrum showed absorption at $211 \mathrm{~nm}$. The EI-MS spectrum displayed molecular ion peak at $m / z 374$, which was more supported by the $\mathrm{FAB}^{+\mathrm{ve}} \mathrm{MS}$ which showed $\mathrm{M}^{+}$ $+\mathrm{H}$ peak at $m / z$ 375. Its molecular formula $\mathrm{C}_{25} \mathrm{H}_{46} \mathrm{~N}_{2}$ was deduced from HREI-MS, which showed molecular ion peak at $\mathrm{m} / z 374.3671$ (calcd for $\mathrm{C}_{31} \mathrm{H}_{48} \mathrm{~N}_{2} \mathrm{O}, 374.3661$ ). The ${ }^{1} \mathrm{H}-$ and ${ }^{13} \mathrm{C}-\mathrm{NMR}$ spectral dara of compound 2 was unambiguously matched with compound $N$-methylpachysamine A. ${ }^{13}$

Compound 3, $[\alpha]_{\mathrm{D}}{ }^{20}=-35(c=0.03, \mathrm{MeOH})$, acquired as white needle from the $\mathrm{pH} 9 \mathrm{DCM}$ extract of S. wallichii. The UV spectrum demonstrated absorption at $209 \mathrm{~nm}$. The IR spectrum exhibited characteristic absorptions at $1516(\mathrm{C}=\mathrm{C})$ and $2903\left(\mathrm{CH}\right.$ stretching) $\mathrm{cm}^{-1}$. The EI-MS spectrum displayed molecular ion peak at $m / z 372$, which was supported by the $\mathrm{FAB}^{+\mathrm{ve}} \mathrm{MS}$ which showed $\left[\mathrm{M}^{+}+\mathrm{H}\right]$ peak at $m / z$ 373. Its molecular formula $\mathrm{C}_{25} \mathrm{H}_{44} \mathrm{~N}_{2}$ was deduced from HREI-MS, which showed molecular ion peak at $m / z 372.3524$ (Calcd. $\mathrm{C}_{25} \mathrm{H}_{44} \mathrm{~N}_{2}=372.3504$ ), The EI MS displayed the three fragments at $\mathrm{m} / z 84$ (64.1\%) and 357 (9.1\%) and $72(100 \%)$. The presence of fragments ion in EI MS at $\mathrm{m} / z 84$ suggested a 3(dimethyl amino) pregnane skeleton. The ${ }^{1} \mathrm{H}$ - and ${ }^{13} \mathrm{C}-\mathrm{NMR}$ spectral data of compound 3 was unambiguously matched with compound sarcodinine. ${ }^{13}$ 


\section{J. Nepal Chem. Soc., Vol. 37, 2017}

Compound 4 was isolated from basic DCM fraction after chromatography over neutral alumina using hexanes/acetone/diethyl amine as an eluting agent. Absorptions at $209 \& 194 \mathrm{~nm}$ were appeared on UV spectrum. The IR spectrum exhibited characteristic absorptions at $3650(\mathrm{NH}), 1658(\mathrm{C}=\mathrm{O}) \mathrm{cm}^{-1}$. The EIMS spectrum displayed molecular ion peak at $m / z 388$, which was more supported by the $\mathrm{FAB}^{+\mathrm{ve}} \mathrm{MS}$ which showed $\mathrm{M}^{+}+\mathrm{H}$ peak at $\mathrm{m} / z$ 389. Its molecular formula $\mathrm{C}_{25} \mathrm{H}_{44} \mathrm{~N}_{2} \mathrm{O}$, was deduced from HREI-MS, which showed molecular ion peak at $m / z 388.3446\left(\right.$ Calcd. $\left.\mathrm{C}_{25} \mathrm{H}_{44} \mathrm{~N}_{2} \mathrm{O}=388.3453\right)$. The EI MS displayed the two fragments at $m / z 373(4.2 \%)$ and $72(100 \%)$. The ${ }^{1} \mathrm{H}$ - and ${ }^{13} \mathrm{C}-\mathrm{NMR}$ spectral data of compound 3 was unambiguously matched with compound sarcorine. ${ }^{13}$

Dichloromethane fraction at $\mathrm{pH} 9$ showed significant activity against $L$. tropica followeed by DCM fraction at $\mathrm{pH}$ 7. Compounds 1-4 all showed significant activity against $L$. tropica (Table-1).

Table-1: Antileishmanial activity of compounds 1-4.

\begin{tabular}{|l|l|}
\hline Compounds & $\begin{array}{l}\text { IC }_{\mathbf{5 0}} \pm \text { SEM }^{\mathbf{a}}(\boldsymbol{\mu} \mathbf{g} / \mathbf{m L}) \\
\text { L. } \text { tropica }\end{array}$ ATCC \\
\hline $\mathbf{1}$ & $18.9 \pm 0.7$ \\
$\mathbf{2}$ & $37.1 \pm 0.8$ \\
$\mathbf{3}$ & $29.9 \pm 0.01$ \\
$\mathbf{4}$ & $30.1 \pm 0.1$ \\
pH 9 DCM fraction & $11.68 \pm 0.06$ \\
pH 7 DCM fraction & $18.5 \pm 0.6$ \\
Pentamidine & $5.09 \pm 0.09$ \\
\hline
\end{tabular}

$\mathrm{SEM}^{\mathrm{a}}$ is the standard error of the mean, Pentamidine* standard inhibitor for antileishmanial

assay

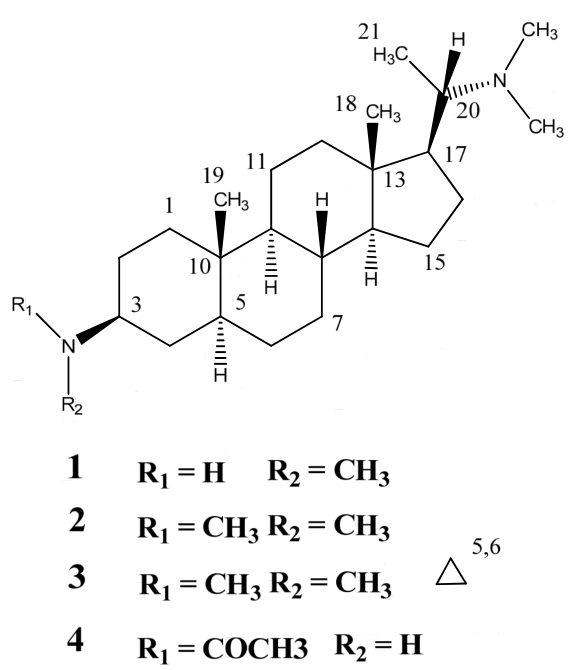

Figure 1: Structures of compounds 1-4. 


\section{Conclusions}

Extract and pure compounds from the plant $S$. wallichii showed good antileishmanial activity against L. tropica. So plants of genus Sarcococca are potential source of antileishmanial compounds and extract of this plant can be developed as ointment for cutaneous leishmaniasis.

\section{Acknowledgements}

Authors are thankful to Prof. Dr. M. Iqbal Choudhary, Director, ICCBS, University of Karachi, for providing lab to conduct antileishmanial activity.

\section{References}

1. Atta-ur-Rahman, Z.-u.-Haq, A. Khalid, S. Anjum, M. R. Khan, and M. I. Choudhary, Helv. Chim. Acta, 2002, 85, 678-688.

2. N. Rai, B. Adhikari, A. Paudel, K. Masuda, R. Mckelvey, and M. Manandhar, J. Nepal Chem. Soc. 2006, 21, 1-7.

3. J. Chakravarty, and S. Shyam, J. Glob. Infect. Dis. 2010, 2 (2) 167-176.

4. A. A. Alrajhi, E. A. Ibrahim, E. B. DeVol, M. Khairat, R. M. Faris, and J. H. Maguire, N. Engl. J. Med. 2002, 346, 891-895.

5. V. J. Ram and M. P. Nath, Curr. Med. Chem. 1996, 3, 303-316.

6. T. Kam, K. Sim, T. Kayono, M. Toyoshima, and K. Hayashi, J. Nat. Prod. 1998, 61, 13321336.

7. K. P. Devkota, M. I. Choudhary, R. Ranjit, Samreen, and N. Sewald. Nat. Prod. Res. 2007, 21 (4), 292-297.

8. M. I. Choudhary, A. Adhikari, Samreen, and A. U. Rahman. J. Chem. Soc. Pak. 2010, 32, 799802.

9. A. Adhikaria, M. I. Vohra, A. Jabeen, N. Dastagir, and M. I. Choudhary. Nat. Prod. Commun. 2015, 10 (9), 1533-1536.

10. S. Habtemariam BMC Pharmacol. 2003, 3:1-6.

11. M. C. Sousa, R. Varandas, R. C. Santos, M. S. Rosa, V. Alves, and J. A. R. Salvador, PLoS ONE. 2014, 9(3):e89939.

12. K. P. Devkota, B. N. Lenta, P. A. Fokou, and N. Sewald, Nat. Prod. Rep. 2008, 25, 612-630.

13. M. I. Choudhary, K. P. Devkota, S. A. Nawaz, and F. Shaheen, Helv. Chim. Acta, 2004, 87, 1099-1108 